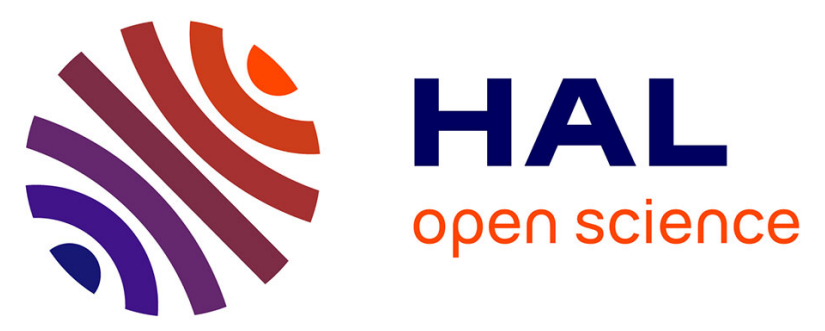

\title{
Reaction and Transport Interplay in Al MOCVD Investigated Through Experiments and Computational Fluid Dynamic Analysis
}

Theodora C. Xenidou, Nathalie Prud'homme, Constantin Vahlas, Nicholas C. Markatos, Andreas G. Boudouvis

\section{To cite this version:}

Theodora C. Xenidou, Nathalie Prud'homme, Constantin Vahlas, Nicholas C. Markatos, Andreas G. Boudouvis. Reaction and Transport Interplay in Al MOCVD Investigated Through Experiments and Computational Fluid Dynamic Analysis. Journal of The Electrochemical Society, 2010, vol. 157 ( ${ }^{\circ}$ 12), pp. 633-641. 10.1149/1.3493617 . hal-01180142

\section{HAL Id: hal-01180142 \\ https://hal.science/hal-01180142}

Submitted on 24 Jul 2015

HAL is a multi-disciplinary open access archive for the deposit and dissemination of scientific research documents, whether they are published or not. The documents may come from teaching and research institutions in France or abroad, or from public or private research centers.
L'archive ouverte pluridisciplinaire HAL, est destinée au dépôt et à la diffusion de documents scientifiques de niveau recherche, publiés ou non, émanant des établissements d'enseignement et de recherche français ou étrangers, des laboratoires publics ou privés. 


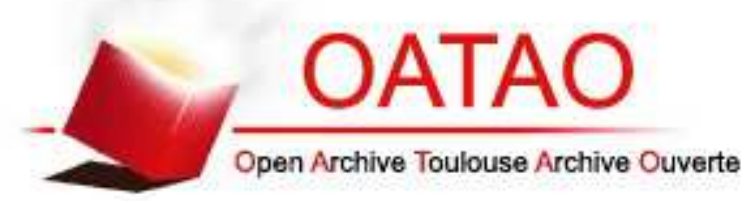

\section{Open Archive TOULOUSE Archive Ouverte (OATAO)}

OATAO is an open access repository that collects the work of Toulouse researchers and makes it freely available over the web where possible.

This is an author-deposited version published in : http://oatao.univ-toulouse.fr/ Eprints ID : 14108

To link to this article : doi: $10.1149 / 1.3493617$

URL : http://dx.doi.org/10.1149/1.3493617

To cite this version : Xenidou, Theodora C. and Prud'homme, Nathalie and Vahlas, Constantin and Markatos, Nicholas C. and Boudouvis, Andreas G. Reaction and Transport Interplay in Al MOCVD Investigated Through Experiments and Computational Fluid Dynamic Analysis. (2010) Journal of The Electrochemical Society (JES), vol. 157 ( $\mathrm{n}^{\circ}$ 12). pp. 633-641. ISSN 0013-4651

Any correspondance concerning this service should be sent to the repository administrator: staff-oatao@ listes-diff.inp-toulouse.fr 


\title{
Reaction and Transport Interplay in Al MOCVD Investigated Through Experiments and Computational Fluid Dynamic Analysis
}

\author{
Theodora C. Xenidou, ${ }^{\text {a,z }}$ Nathalie Prud'homme, ${ }^{\text {b,c }}$ Constantin Vahlas, ${ }^{\text {b }}$ \\ Nicholas C. Markatos, ${ }^{\mathrm{a}}$ and Andreas G. Boudouvis ${ }^{\mathrm{a}}$ \\ ${ }^{a}$ School of Chemical Engineering, National Technical University of Athens, Athens 15780, Greece \\ ${ }^{b}$ Centre Interuniversitaire de Recherche et d'Ingénierie des Matériaux, Ecole Nationale Supérieure \\ d'Ingénieurs en Arts Chimiques et Technologiques, 31030 Toulouse Cedex 4, France
}

\begin{abstract}
An improved reactive transport model of a metallorganic chemical vapor deposition process for the growth of aluminum films from dimethylethylamine alane is developed. The computational fluid dynamics model is built under PHOENICS software for the simulation of the coupled fluid flow, heat transfer, and chemistry. The growth mechanism of aluminum films is based on wellestablished, in the literature, reaction order and activation energy of gas-phase and surface reactions. The improvement of the model against a simplified model is established. The interplay of reaction and transport is elucidated. In particular, the important effects of the gas-phase reaction and of the showerhead system are revealed; accounting for gas-phase along with surface reactions for the flow details in the showerhead and for the three-dimensional geometry induced by the distribution of the holes in the showerhead yields substantial enhancement of the predictive capability of the model. The satisfactory agreement between model predictions and growth-rate measurements allows one to understand and improve the process. The model is further used to investigate the effect of key operating parameters on the characteristics of the aluminum films. Simulation results are suggestive of modifications in the operating parameters that could enhance the growth rate and its spatial uniformity.
\end{abstract}

Aluminum (Al) is the major element in complex metallic alloys (CMAs), including quasicrystalline phases, such as the $\mathrm{Al}_{62} \mathrm{Cu}_{25} \mathrm{Fe}_{13}$ icosahedral one. ${ }^{1}$ Such phases present strong technological potential due to their interesting properties and combination of properties. ${ }^{2}$ This is especially the case for CMA films, applied on complex-inshape substrates. Metallorganic chemical vapor deposition (MOCVD) is a promising technique to meet this challenge and for this reason the growth of $\mathrm{Al}$ films was selected as the first important step toward the establishment of a robust, innovative MOCVD process for the production of CMA films.

Although MOCVD is essentially a chemical surface process, transport phenomena are very complex in MOCVD reactors ${ }^{3}$ and the accurate control of the growth of films brings together various aspects of fluid flow, heat transfer, and chemical kinetics. ${ }^{4,5}$ Extended experimentation is required to determine operating conditions for process optimization. Alternatively, modeling of the MOCVD process and simulation at appropriately selected conditions could make the time-consuming experimental investigation more efficient. ${ }^{6-9}$ Preliminary results of the supplementary use of growth experiments and computational fluid dynamics (CFD) simulations of Al MOCVD process from dimethylethylamine alane (DMEAA) have already been published by the authors. ${ }^{10}$ The selection of DMEAA as the metal-organic precursor for $\mathrm{Al}$, was based on the results of previous experimental studies on its decomposition ${ }^{11-19}$ and on the subsequent deposition of aluminum films. ${ }^{20,21}$ The published results concerned the simulation of $\mathrm{Al}$ growth in the narrow temperature range of $200-220^{\circ} \mathrm{C}$ and they provided an insight into the hydrodynamics and the thermal patterns of the MOCVD reactor to be used in the future production of the Al-based CMAs.

In the present work, the experimental investigation of Al growth in an expanded temperature range enhances the improvement of a simple starting model, ${ }^{10}$ which is now ready to be used in the thorough investigation of the MOCVD of Al-based multinary intermetallic films. Specifically, complementary measurements were obtained in the temperature range of $160-260^{\circ} \mathrm{C}$ at 10 Torr and concerned the dependence of the growth-rate profile on the process temperature, on the distance between the gas delivery system and

\footnotetext{
${ }^{c}$ Present address: University Paris Sud 11, LEMHE/ICMMO, Orsay Cedex, France

${ }^{\mathrm{z}}$ E-mail: thexen@central.ntua.gr
}

the heated substrate, and on the use of the perforated plate of the showerhead system. The complete set of the experimental data was utilized to formulate a comprehensive reactive transport model for Al-MOCVD based on PHOENICS CFD software. ${ }^{22,23}$ The aim of this work is to reproduce the experimental measurements through realistic CFD modeling and, more importantly, to contribute to the understanding of $\mathrm{Al}$ from DMEAA under subatmospheric pressure conditions.

DMEAA has been experimentally investigated as a precursor for aluminum films by several groups. ${ }^{11-19}$ Plausible reaction pathways of DMEAA dissociation were suggested to explain the observations. ${ }^{12,14,24}$ Kinetic parameters, such as reaction order and activation energy, were reported for chemical reactions in the gas phase and on the surface. ${ }^{16,17}$ According to these experimental observations, the $\mathrm{Al}$ growth rate increased to a maximum around $150^{\circ} \mathrm{C}$ and then decreased at substrate temperature above $150^{\circ} \mathrm{C} .{ }^{17}$ The activation energy of the surface reaction was found to be $9.96 \mathrm{kcal} / \mathrm{mol}$ when the substrate temperature was lower than $150^{\circ} \mathrm{C}$, which is believed to be in the surface-reaction-limited regime. The gas-phase reaction mechanism in Al MOCVD from DMEAA was investigated using in situ real-time FTIR spectroscopy. ${ }^{16}$ The gas-phase dissociation reaction of DMEAA into dimethylamine (DMEA) and alane was found to be first order with activation energy of $9.56 \mathrm{kcal} / \mathrm{mol}$. Moreover, the gas-phase DMEAA was unstable even at room temperature, resulting in dissociation into DMEA and alane, and the dissociation rate accelerated at higher values of gas temperature. Matsuhashi et al. ${ }^{25}$ revealed an increase of the pressure in a DMEAA container from 0.5 to 200 Torr in $500 \mathrm{~h}$ at ambient temperature. The alane is also known to be very unstable in the gas phase and forms a dimer, trimer, and even a polymer. ${ }^{26}$ When the substrate temperature is higher than $150^{\circ} \mathrm{C}$, it is believed that alane can be readily polymerized and it is not readily adsorbed on the surface to form aluminum films. ${ }^{12}$ The rapid dissociation of DMEAA in the gas phase brings about the decrease of the growth rate when the substrate temperature is above $150^{\circ} \mathrm{C}$. A similar effect of temperature on the behavior of DMEAA was also reported by Jang et al.; ${ }^{18}$ the temperature where the maximum growth rate was obtained was $160^{\circ} \mathrm{C}$, to be compared with $150^{\circ} \mathrm{C}$ in the work by Yun et al. ${ }^{17}$ It was also reported that when temperature is below $160^{\circ} \mathrm{C}$, it is very difficult to distinguish a mass-transport-limited regime from a surface-reaction-limited one. 


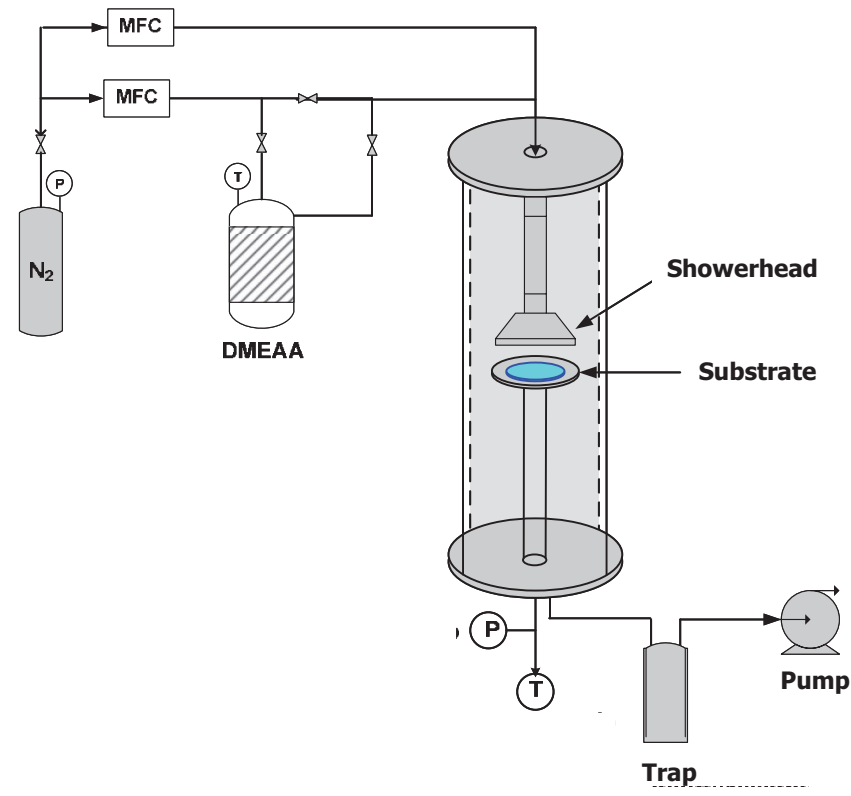

Figure 1. (Color online) Schematic illustration of the experimental MOCVD setup.

All these experimental findings are taken into account in the present reactive transport model, which is a more elaborate version of the one presented earlier. ${ }^{10}$ The effect of reactive transport in the gas phase is added to the surface chemistry to account for the decrease of the $\mathrm{Al}$ growth rate at higher values of temperature. The detailed description of the perforated plate of the showerhead system, in a three-dimensional reactor discretization, further improves the accuracy of the model predictions. The improved model is then used to investigate the effect of key operating parameters on $\mathrm{Al}$ growth rate and its spatial uniformity over the surface of the heated substrate.

\section{Experimental}

Growth experiments of $\mathrm{Al}$ films were performed in the experimental setup schematically illustrated in Fig. 1. This MOCVD setup is composed of a stagnant flow, cylindrical, vertical, stainless steel reactor, the dimensions of which were reported previously. ${ }^{10}$ The deposition chamber is made of double envelope, allowing the wall temperature to be monitored through the circulation of thermally regulated silicon oil. $\mathrm{HF}$ cleaned $5 \times 10 \mathrm{~mm}$ silicon coupons were used as substrates. They were positioned horizontally at different places on a $58 \mathrm{~mm}$ diameter susceptor and heated by a resistance coil gyred just below the surface of the susceptor. The input gas is

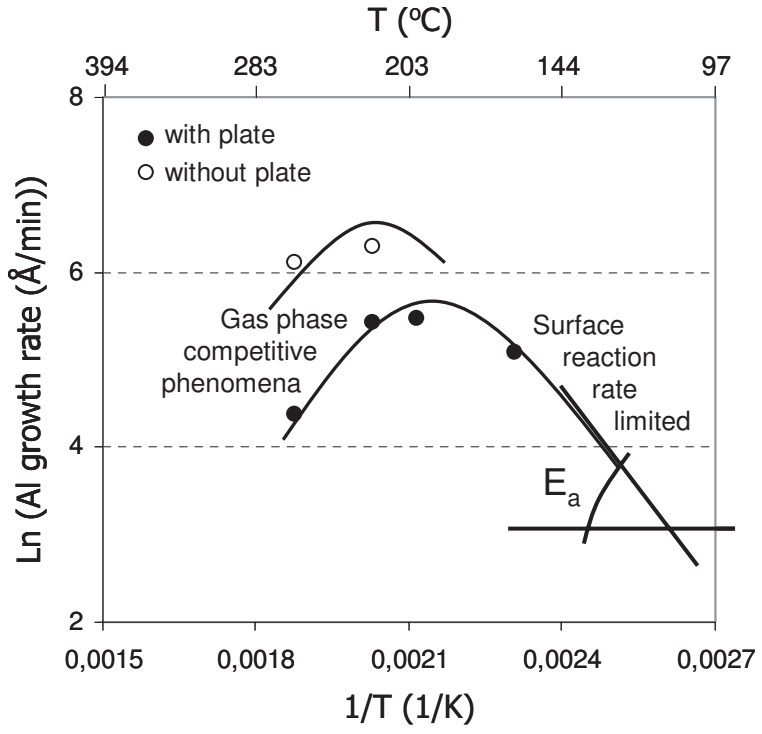

Figure 2. Arrhenius plot of the growth rate of Al films as a function of substrate temperature, with and without the use of the shower plate.

distributed though a showerhead system containing a $60 \mathrm{~mm}$ diameter perforated plate. The base pressure of reactor is $10^{-6}$ Torr, while the total pressure was fixed at 10 Torr.

99\% pure DMEAA (Epichem) was used as received in a stainless steel bubbler. It was maintained at $9^{\circ} \mathrm{C}$, corresponding to a saturated vapor pressure of 0.7 Torr. The DMEAA bubbler was maintained at this temperature during the entire period of its service in order to avoid degradation of the precursor. ${ }^{25} 99.9992 \%$ pure $\mathrm{N}_{2}$ (Air Products) was fed through two electropolished stainless steel gas lines with VCR fittings. One line was used for bubbling through the Al precursor and the other for the dilution of the input gas. The flow rate of the dilution $\mathrm{N}_{2}$ was $305 \mathrm{sccm}$, while the bubbling $\mathrm{N}_{2}$ flow rate was $25 \mathrm{sccm}$. Assuming saturation of the gas phase, these conditions lead to an upper limit of the flow rate of DMEAA equal to $2 \mathrm{sccm}$.

Table I summarizes the operating conditions and the results of the growth experiments. In the first four experiments (expl, $1=1,4)$ the perforated shower plate of the gas delivery system was used, while in the last four experiments (expl, $1=5,8)$, the plate was removed from the showerhead system. Growth rate was measured at certain positions over the substrate, through the weight gain of each sample. Figure 2 depicts the average growth rate of Al films on $\mathrm{Si}$ substrates as a function of substrate temperature, in the range of $160-260^{\circ} \mathrm{C}$. Only experiments corresponding to a $15 \mathrm{~mm}$ distance between the perforated shower plate and the heated substrate are included in the Arrhenius plot. As shown in Fig. 2, the growth rate

Table I. Experimental operating conditions and results for the growth of Al films.

\begin{tabular}{|c|c|c|c|c|c|c|c|}
\hline Case & $\begin{array}{l}\text { Sample } \\
\text { name }\end{array}$ & $\begin{array}{c}\text { Growth } \\
\text { temperature, } \\
\mathrm{T}_{\mathrm{s}} \\
\left({ }^{\circ} \mathrm{C}\right)\end{array}$ & $\begin{array}{c}\text { Wall } \\
\text { temperature, } \\
\mathrm{T}_{\mathrm{w}} \\
\left({ }^{\circ} \mathrm{C}\right)\end{array}$ & $\begin{array}{c}\text { Inlet } \\
\text { temperature, } \\
\mathrm{T}_{\text {in }} \\
\left({ }^{\circ} \mathrm{C}\right)\end{array}$ & $\begin{array}{c}\text { Plate- } \\
\text { substrate } \\
\text { distance, } \\
\mathrm{D}_{\mathrm{p}-\mathrm{s}}(\mathrm{mm})\end{array}$ & $\begin{array}{c}\text { Deposition } \\
\text { duration, } \\
t_{d} \\
(\mathrm{~min})\end{array}$ & $\begin{array}{c}\text { Average } \\
\text { growth rate, } \\
\overline{\mathrm{GR}} \\
(\AA / \mathrm{min})\end{array}$ \\
\hline \multirow{4}{*}{$\begin{array}{l}\text { I: with } \\
\text { shower } \\
\text { plate }\end{array}$} & exp1 & 160 & 25 & 65 & 15 & 120 & 161.6 \\
\hline & exp2 & 200 & 25 & 65 & 15 & 120 & 237.8 \\
\hline & exp3 & 220 & 25 & 65 & 15 & 120 & 227.2 \\
\hline & exp4 & 260 & 25 & 65 & 15 & 120 & 79.0 \\
\hline \multirow{4}{*}{$\begin{array}{l}\text { II: without } \\
\text { shower } \\
\text { plate }\end{array}$} & exp5 & 220 & 25 & 67 & 15 & 120 & 544.6 \\
\hline & exp6 & 240 & 75 & 75 & 20 & 30 & 335.3 \\
\hline & exp7 & 260 & 25 & 25 & 15 & 120 & 453.5 \\
\hline & exp8 & 260 & 50 & 75 & 21 & 50 & 418.5 \\
\hline
\end{tabular}


of $\mathrm{Al}$ films increases as the substrate temperature increases up to $200^{\circ} \mathrm{C}$ when the shower plate is used. On the contrary, the $\mathrm{Al}$ growth rate decreases with further increase of substrate temperature above $200^{\circ} \mathrm{C}$. This trend is observed for both cases examined, i.e., with and without the use of the shower plate, and is consistent with previous experimental findings cited in the introduction. It is worth mentioning that the objective of the reported experimental part was to provide data on the growth rate of $\mathrm{Al}$ films under different deposition conditions rather than to propose another value of the activation energy of the growth process.

\section{The Reactive Transport Model}

The starting point for the present work is a simplified CFD model constructed by Xenidou et al. ${ }^{10}$ to simulate the hydrodynamic and thermal flow of the MOCVD reactor, including an overall surface reaction to account for the growth of Al films from DMEAA. The present reactive transport model includes two important refinements that account more reliably for the reactor configuration and for the growth chemistry; the first refinement concerns the transport model while the second one is an addition to the reactive model. For reasons of completeness, the main features of the reactive transport model are presented below followed by the detailed description of the model improvements.

The reactive transport model for the MOCVD process relates the physicochemical phenomena occurring in the reactor to the properties of the Al films. The core of the model is formed by the transport model describing the gas flow and transport of energy and species in the reactor. The basic components of the reactive model are (i) a gas-phase chemistry part, including the reaction path and rate constant for the homogeneous reaction, which influences the species concentration distribution near the growth surface, and (ii) a surface chemistry part which describes how reactions between gas-phase species and adsorbed species on the surface lead to the film growth. The coupling of transport phenomena and chemistry under the framework of computational fluid dynamics is the master approach followed in the simulation of chemical vapor deposition (CVD) processes. Following the first publications on CVD reactor modeling in the late 70 s and early 80 's, ${ }^{27-29}$ the computational analyses of CVD processes have been based on CFD models that combine either multidimensional flow with rather simple chemistry ${ }^{30-33}$ or simple zero or one-dimensional flow with detailed gas-phase and surface chemical reactions. ${ }^{34-37}$ Since the late 90 's, however, the combination of multidimensional fluid dynamics with multireaction chemistry has become feasible due to the increasing availability of computational power and efficiency. ${ }^{5,38,39}$ More detailed overview of the development of CVD simulation models in the past decades can be found in Ref. 5. In recent years, successful attempts have been made in employing CFD models to optimize CVD process conditions ${ }^{40,41}$ and hydrodynamic design of CVD reactors ${ }^{42}$ with respect to growth-rate uniformity. The present reactive transport model is based on the state-of-the-art approach that combines three-dimensional fluid dynamics with homogeneous and heterogeneous reactions, enabling a realistic description of the transport phenomena and of the growth process inside the MOCVD reactor. Such an approach ensures that the present model can be used as a reliable tool in the optimization of the reactor design; the framework for this work has been recently developed combining the simplified model of the MOCVD process with evolutionary algorithms. ${ }^{43}$

The transport phenomena in the gas mixture are described by the conservation equations of mass, momentum, and energy, coupled to the conservation equations for the individual chemical species, under the following reasonable assumptions: the gas multicomponent mixture is treated as a continuum; laminar gas flow conditions exist; steady-state conditions prevail; the equation of state obeys the ideal gas law. The reader is referred to earlier work ${ }^{10}$ for detailed discussion of the simplifying assumptions. The complete set of the nonlinear partial differential equations is as follows: ${ }^{44}$

Mass balance:

$$
\nabla \cdot(\rho \mathbf{u})=0
$$

Momentum balance:

$$
\begin{aligned}
\nabla \cdot(\boldsymbol{u} \mathbf{u})= & -\nabla \mathbf{P}+\rho \mathbf{g}+\nabla \cdot\left[\mu\left(\nabla \mathbf{u}+(\nabla \mathbf{u})^{T}\right)\right. \\
& \left.-\frac{2}{3} \mu(\nabla \cdot \mathbf{u}) \mathbf{I}\right]
\end{aligned}
$$

Energy balance:

$$
c_{p} \nabla \cdot(\rho \mathbf{u T})=\nabla \cdot(\lambda \nabla \mathrm{T})-\sum_{\mathrm{i}=1}^{\mathrm{N}} \mathbf{j}_{\mathrm{i}} \cdot \frac{\Delta \mathrm{H}_{\mathrm{i}}}{\mathrm{M}_{\mathrm{i}}}-\sum_{\mathrm{i}=1}^{\mathrm{N}} \sum_{\mathrm{k}=1}^{\mathrm{K}} \mathrm{H}_{\mathrm{i}} \gamma_{\mathrm{ik}} \mathrm{R}_{\mathrm{k}}^{\mathrm{g}}
$$

Species balance:

$$
\begin{aligned}
\nabla \cdot\left(\rho \mathbf{u} \omega_{\mathrm{i}}\right)= & -\nabla\left(-\rho \mathrm{D}_{\mathrm{i}}^{\text {eff }} \nabla \omega_{\mathrm{i}}-\rho \omega_{\mathrm{i}} \mathrm{D}_{\mathrm{i}}^{\text {eff }} \nabla(\ln \mathrm{M})\right. \\
& \left.+\mathrm{M} \omega_{\mathrm{i}} \mathrm{D}_{\mathrm{i}}^{\text {eff }} \sum_{\mathrm{j}=1, \mathrm{j} \neq \mathrm{i}}^{\mathrm{N}} \frac{\mathrm{j}_{\mathrm{j}}^{\mathrm{C}}}{\mathrm{M}_{\mathrm{j}} \mathrm{D}_{\mathrm{ij}}}-\mathrm{D}_{\mathrm{i}}^{\mathrm{T}} \nabla(\ln \mathrm{T})\right) \\
& +\mathrm{M}_{\mathrm{i}} \sum_{\mathrm{k}=1}^{\mathrm{K}} \gamma_{\mathrm{ik}} \mathrm{R}_{\mathrm{k}}^{\mathrm{g}}
\end{aligned}
$$

The transport equations are subject to the following boundary conditions for velocity field, temperature profile, and species concentration distribution: (i) at the inlet, the velocity distribution is considered uniform, the gas feed is assumed to be at constant temperature, and the species mass fractions are set to the experimental values; (ii) the operating pressure is specified at the outlet, where zero normal derivatives are assumed for all other variables $\phi(\phi$ $=\mathrm{T}, \mathrm{u}_{\mathrm{x}}, \mathrm{u}_{\mathrm{z}}, \mathrm{u}_{\mathrm{y}}, \omega_{\mathrm{i}}$ ); (iii) the no-slip condition for gas velocity is applied at any solid surface; (iv) the temperature is fixed at the outer walls of the reactor; and (v) the temperature is fixed inside the susceptor at a position of 3-4 $\mathrm{mm}$ from the substrate surface; it is the position where the thermocouple is located. A conjugate heat transfer model is used to calculate the temperature inside the susceptor and on the substrate surface.

The properties of the individual gas species and the binary diffusion coefficients are estimated using the kinetic gas theory. ${ }^{45} \mathrm{De}-$ tailed description of mixing rules used for the calculation of the properties of the multicomponent gas mixture in terms of pressure, temperature, and composition is given in earlier work. ${ }^{46}$ The Lennard-Jones parameters of the individual chemical species are taken from Choi et al. ${ }^{47}$

The deposition rate was described by the formula adopted by many researchers ${ }^{48,49}$ that combines surface reaction and gas-phase diffusion of reactive species through the boundary layer,

$$
\frac{1}{\mathrm{R}_{\mathrm{d}}}=\frac{1}{\mathrm{R}^{\mathrm{S}}}+\sum_{\mathrm{i}=1}^{\mathrm{N}} \frac{\sigma_{\mathrm{i}}}{\mathrm{R}_{\mathrm{i}}^{\mathrm{D}}}
$$

The calculated deposition rate $\mathrm{R}_{\mathrm{d}}\left(\mathrm{mol} / \mathrm{m}^{2} \mathrm{~s}\right)$ was converted to the experimentally measured growth rate, GR $(\AA / \mathrm{min})$ as

$$
\mathrm{GR}=6 \times 10^{11} \mathrm{R}_{\mathrm{d}} \frac{\mathrm{M}_{\mathrm{s}}}{\rho_{\mathrm{s}}}
$$

The variation of the growth rate is calculated through the maximum, minimum, and average growth rate, i.e., by

$$
\Delta \mathrm{G}=\frac{\mathrm{GR}_{\max }-\mathrm{GR}_{\min }}{\overline{\mathrm{GR}}}
$$

The transport equations for mass, momentum, energy, and chemical species described above have the general form ${ }^{50}$ 


$$
\nabla \cdot(\rho \mathbf{u} \phi)=\nabla \cdot\left(\Gamma_{\phi} \nabla \phi\right)+S_{\phi}^{0}+S_{\phi}^{\prime} \phi
$$

In Eq. 8, the $S_{\phi}=S_{\phi}^{0}+S_{\phi}^{\prime} \phi$ is the generalized source term, linearized in variable $\phi$. To numerically solve these equations, PHOENICS CFD software was used, ${ }^{22}$ which is based on the finite volume method. ${ }^{50}$ The momentum and continuity equations were coupled through the SIMPLEST (Semi-Implicit Method for Pressure-Linked Equations ShorTened) scheme and the upwind differencing scheme was used for the convective terms. The discretized transport equations were solved in a segregated way, i.e., the coupling between the velocity components, the pressure correction, the temperature, and each of the species mass fractions is accounted for through iteration. To ensure convergence, linear relaxation was used for pressure correction and temperature and false time step relaxation was applied to all other variables.

Improvement 1.- While the axial symmetry of the vertical MOCVD reactor supports the two-dimensional (2D) approximation of the reactor, the nonuniform distribution of the holes over the shower plate requires a three-dimensional (3D) simulation. In the starting simplified model, ${ }^{10}$ the MOCVD reactor was spatially discretized in 2D curvilinear coordinates based on the assumption of axial symmetry of the vertical reactor. The latter assumption was supported by the approximate treatment used to simulate the flow through the perforated plate. According to that approximation, the shower plate was not included in the solution domain and the corresponding control volumes were treated as solid. To overcome the discontinuity of the flow in the solution domain, the pressure loss due to friction was specified using the Darcy-Weisbach equation for laminar flow, ${ }^{51}$

$$
\Delta \mathrm{P}=32 \mu \mathrm{u}_{\mathrm{z}} \frac{\mathrm{L}}{\mathrm{d}^{2}}
$$

In the present improved model, the reactor is discretized in $3 \mathrm{D}$ curvilinear coordinates to account for the detailed configuration of the perforated shower plate as shown in Fig. 3. The shower plate consists of 1450 holes of $0.76 \mathrm{~mm}$ diameter. The thickness of the plate is $1 \mathrm{~mm}$. In this case, the approximate boundary condition described above was removed and the computational domain was extended inside the plate for the gas flow through the plate to be adequately resolved; this required a finer computational grid inside the holes of the plate.

Improvement 2.- In the preliminary analysis of the MOCVD reactor, in the temperature range of $200-220^{\circ} \mathrm{C}$, a fast reaction was assumed to occur on the substrate surface in one step according to

$\left[\left(\mathrm{CH}_{3}\right)_{2} \mathrm{C}_{2} \mathrm{H}_{5}\right] \mathrm{NAlH}_{3}(\mathrm{~g}) \rightarrow \mathrm{Al}(\mathrm{s})+\left[\left(\mathrm{CH}_{3}\right)_{2} \mathrm{C}_{2} \mathrm{H}_{5}\right] \mathrm{N}(\mathrm{g})+3 / 2 \mathrm{H}_{2}(\mathrm{~g})$

The rate constant was chosen to be large enough for the growth rate to be independent of its value. This assumption is valid in the transport-limited regime where the surface reaction is very fast and the growth rate approaches the diffusive flux of the species to the substrate surface. The rate of consumption of reactants and the rate of production of products were based on the stoichiometry of the overall surface reaction (Eq. 10).

In the present work, to calculate the growth rate of $\mathrm{Al}$ films in the temperature range of $160-260^{\circ} \mathrm{C}$, a reactive model was formulated. It considers both homogeneous and heterogeneous chemical reactions obtained from the literature. ${ }^{16,17}$ Although plausible reaction mechanisms, including adsorption of DMEAA, surface reactions, and desorption of hydrogen and DMEA were reported, ${ }^{14}$ the activation energy is available only for the overall reaction. Thus, the chemical reactions considered in the improved reactive model of the $\mathrm{Al}$ growth process are listed in Table II. The first reaction occurs in the gas phase, resulting in the DMEAA dissociation into DMEA and alane, while the second one occurs on the surface, resulting in the growth of $\mathrm{Al}$ films on the heated substrates. It was assumed that once DMEAA is dissociated in the gas phase, gas-phase alane de-

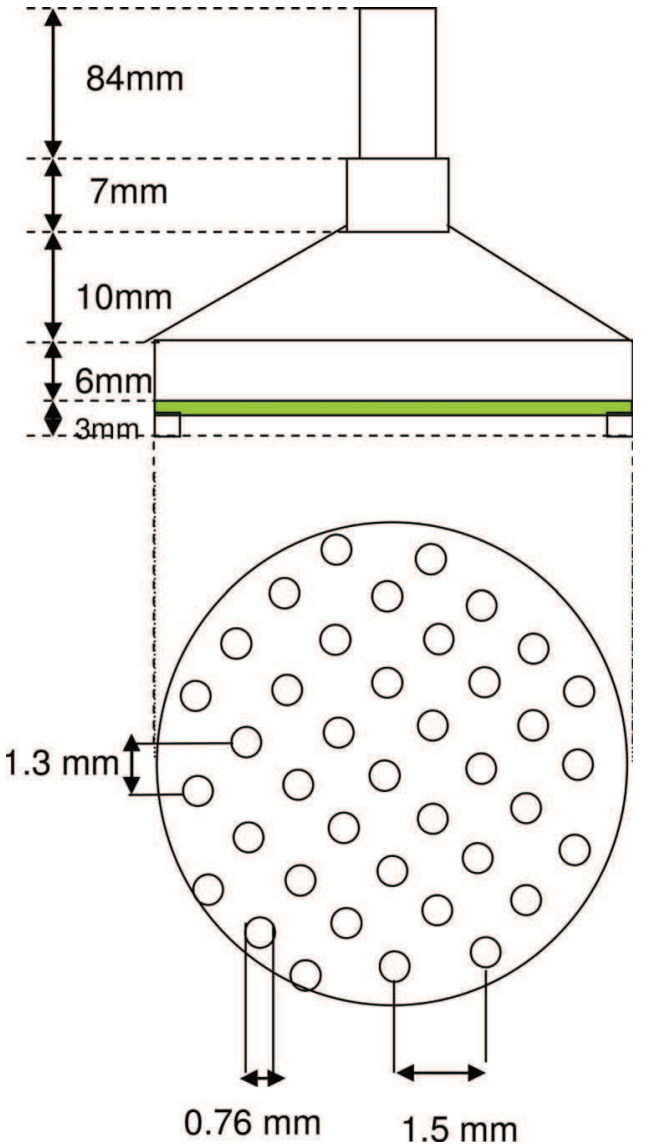

Figure 3. (Color online) Schematic illustration of the showerhead gas delivery system.

composes almost immediately without contributing to the film growth. ${ }^{12,26}$ Thus, the first reaction is responsible for the degradation of DMEAA in the gas phase, resulting in the decrease of the growth rate at higher substrate temperatures. Moreover, the gas-phase reaction was considered to occur only in the forward direction, because the reverse reaction can occur very slowly under a $\mathrm{H}_{2}$ environment. ${ }^{16}$ Note that the activation energy was obtained from the cited references; the pre-exponential factor of the gas-phase reaction was extracted from the Arrhenius plot of the Al-N dissociation reaction-rate constant (see Fig. 6 in Ref. 16). The preexponential factor of the surface reaction was fitted to the experimental data.

\section{Results and Discussion}

Comparison with the simplified model.- At first, the improvement of the present reactive transport model was evaluated in comparison to the reference simplified one. ${ }^{10}$ Figure 4 compares the predictions of the two models with the experimental measurements in terms of the $\mathrm{Al}$ growth-rate profile at growth temperature $\left(\mathrm{T}_{\mathrm{s}}\right)$ of $200^{\circ} \mathrm{C}$ and plate-substrate distance $\left(\mathrm{D}_{\mathrm{p}-\mathrm{s}}\right)$ of $15 \mathrm{~mm}$. The continuous curve is the prediction of the improved model, while the dotted line corresponds to the simplified model. It can be seen that although the simplified model follows the evolution of the experimental growth rate in the radial direction, it fails to capture the rapid increase of the growth rate toward the edge of the substrate, i.e., at $25 \mathrm{~mm}$. On the other hand, the improved model performs much better at the edge of the substrate. Taking into account the experimental error of the growth rate $\left( \pm 8 \AA / \mathrm{min}\right.$ at $\left.200^{\circ} \mathrm{C}\right)$, the predictions of the improved model are very satisfactory. 
Table II. Chemical reactions and rate constants for reaction $k(m=1,2), k_{m}=A_{m} \exp \left(-E_{m} / R T\right)$.

\begin{tabular}{|c|c|c|c|c|c|}
\hline & Reactions & Classification & $\begin{array}{c}\text { Activation } \\
\text { energy } \\
\left(\mathrm{kcal} \mathrm{mol}^{-1}\right)\end{array}$ & $\begin{array}{c}\text { Pre- } \\
\text { exponential } \\
\text { factor }^{\mathrm{a}}\end{array}$ & Ref. \\
\hline 1 & {$\left[\left(\mathrm{CH}_{3}\right)_{2} \mathrm{C}_{2} \mathrm{H}_{5}\right] \mathrm{NAlH}_{3}(\mathrm{~g}) \rightarrow\left[\left(\mathrm{CH}_{3}\right)_{2} \mathrm{C}_{2} \mathrm{H}_{5}\right] \mathrm{N}(\mathrm{g})+\mathrm{AlH}_{3}(\mathrm{~g})$} & Volumetric & 9.56 & $2.4 \times 10^{7}$ & 16 \\
\hline 2 & {$\left[\left(\mathrm{CH}_{3}\right)_{2} \mathrm{C}_{2} \mathrm{H}_{5}\right] \mathrm{NAlH}_{3}(\mathrm{~g}) \rightarrow \mathrm{Al}(\mathrm{s})+\left[\left(\mathrm{CH}_{3}\right)_{2} \mathrm{C}_{2} \mathrm{H}_{5}\right] \mathrm{N}(\mathrm{g})+3 / 2 \mathrm{H}_{2}(\mathrm{~g})$} & Surface & 9.96 & $4.0 \times 10^{0}$ & 18 \\
\hline
\end{tabular}

${ }^{\mathrm{a}}$ The pre-exponential factor in the gas-phase reaction is given in units of $\mathrm{s}^{-1}$ and that of the surface reaction in $\mathrm{m} \mathrm{s}^{-1}$.

Validation of the model.- The improved model is validated against experimental measurements obtained in the MOCVD setup. Remember that the first set of experiments was carried out with the use of the perforated plate while in the second set the plate was removed from the showerhead system. Figure 5 shows the comparison of the model predictions with the experimental growth rates when the perforated plate is used (case I). As shown in Fig. 5a, the

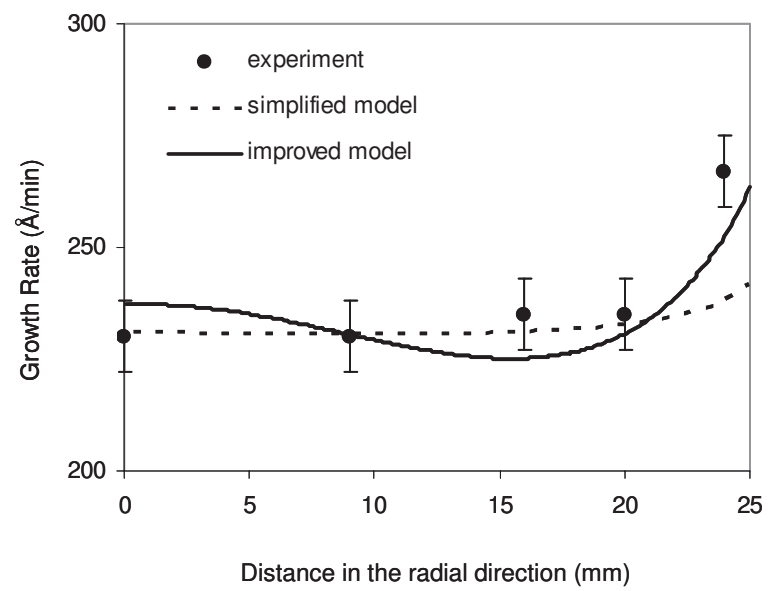

Figure 4. $\mathrm{Al}$ growth rate along the radial direction at $\mathrm{T}_{\mathrm{s}}=200^{\circ} \mathrm{C}$ and $\mathrm{D}_{\mathrm{p}-\mathrm{s}}=15 \mathrm{~mm}$. Experimental measurements vs model predictions.
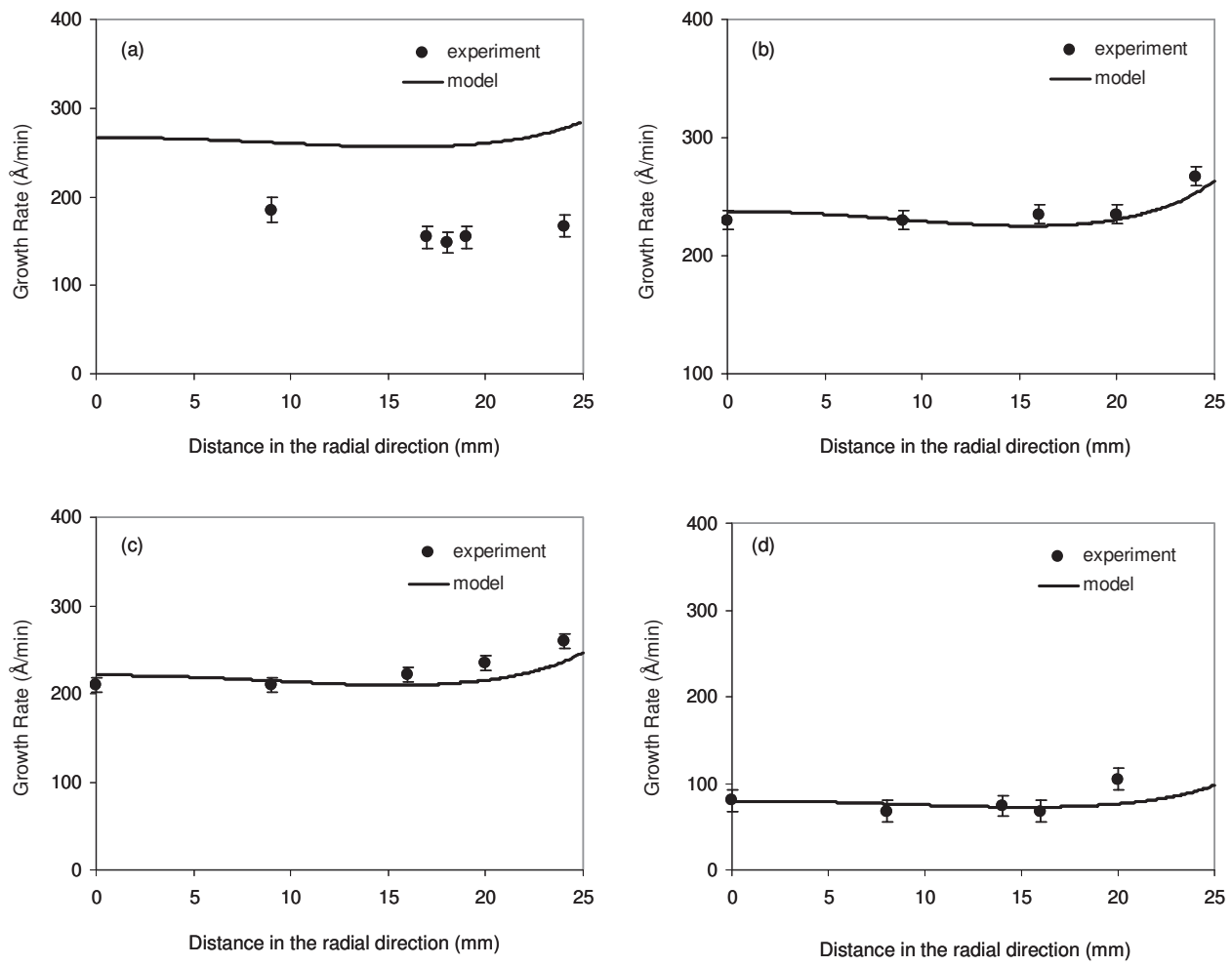
the gas phase. predicted growth rates at $160^{\circ} \mathrm{C}$ are very high compared to the experimentally measured ones. This significant divergence can be explained by the incubation time of Al growth on silicon substrates. According to our experimental observations, the incubation time, during which no appreciable deposition had been observed at $160^{\circ} \mathrm{C}$, was approximately $2 \mathrm{~min}$ at the center of the susceptor and almost $15 \mathrm{~min}$ at its edge; i.e., at $25 \mathrm{~mm}$ from the center. The incubation time was not taken into account in the calculation of the growth rate; that is, the incubation time was not subtracted from the total duration of each experiment. Similar incubation times of $\mathrm{Al}$ growth from DMEAA have also been observed on $\mathrm{Si}$ and $\mathrm{SiO}_{2} .{ }^{14,18}$ In agreement with literature results, the incubation time decreases with increasing deposition temperature in the investigated range of temperature.

The agreement between experimental and predicted growth-rate profiles is satisfactory at higher values of temperature $\left(200-260^{\circ} \mathrm{C}\right)$, as depicted in Fig. 5b-5d. Note that growth rate decreases with increasing $\mathrm{T}_{\mathrm{s}}$, and this trend is also predicted by the improved model. We emphasize that this is the important effect of the second modification of the model, i.e., the addition of the gas-phase reaction which is responsible for the rapid degradation of the Al precursor in

Figure 6 presents the predicted $\mathrm{Al}$ growth rates with experimentally measured ones for case II, i.e., without the shower plate. Note that the model is modified to describe the plate-free showerhead system. According to the experimental measurements, when the shower plate is removed from the gas delivery system, growth rates
Figure 5. Al growth rate along the radial direction, at (a) $\mathrm{T}_{\mathrm{s}}=160^{\circ} \mathrm{C}$, (b) $\mathrm{T}$ $=200^{\circ} \mathrm{C}$, (c) $\mathrm{T}_{\mathrm{s}}=220^{\circ} \mathrm{C}$, and (d) $\mathrm{T}_{\mathrm{s}}$ $=260^{\circ} \mathrm{C}$. Experimental measurements vs model predictions, for the case with the perforated plate, case I. The platesubstrate distance is $\mathrm{D}_{\mathrm{p}-\mathrm{s}}=15 \mathrm{~mm}$. 

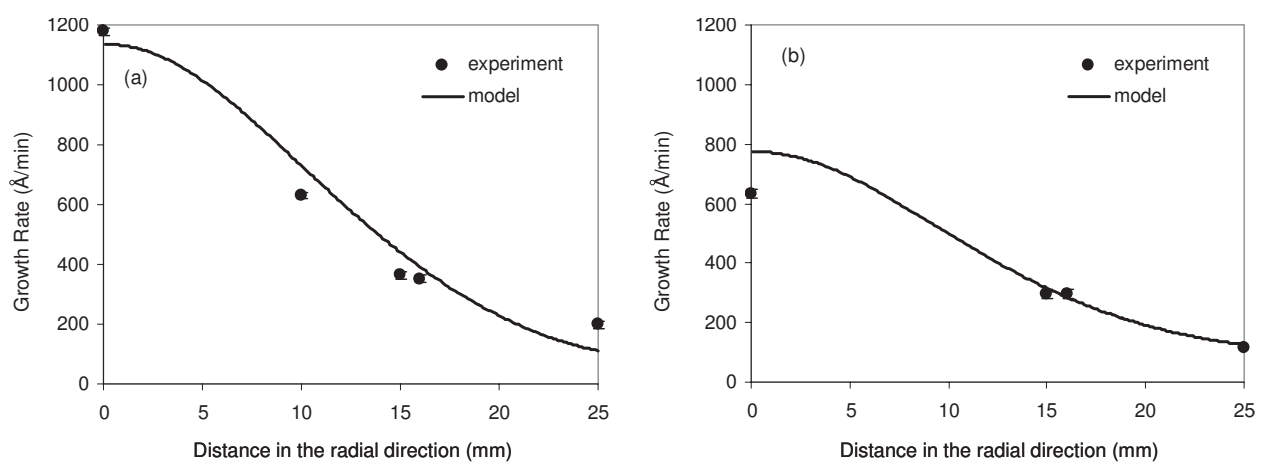

Figure 6. Al growth rate along the radial direction, at (a) $\mathrm{T}_{\mathrm{s}}=220^{\circ} \mathrm{C}, \quad \mathrm{D}_{\mathrm{p}-\mathrm{s}}$ $=15 \mathrm{~mm}$, (b) $\mathrm{T}_{\mathrm{s}}=240^{\circ} \mathrm{C}, \mathrm{D}_{\mathrm{p}-\mathrm{s}}=20 \mathrm{~mm}$, (c) $\mathrm{T}_{\mathrm{s}}=260^{\circ} \mathrm{C}, \mathrm{D}_{\mathrm{p}-\mathrm{s}}=15 \mathrm{~mm}$, and (d) $\mathrm{T}_{\mathrm{s}}=260^{\circ} \mathrm{C}, \mathrm{D}_{\mathrm{p}-\mathrm{s}}=21 \mathrm{~mm}$. Experimental
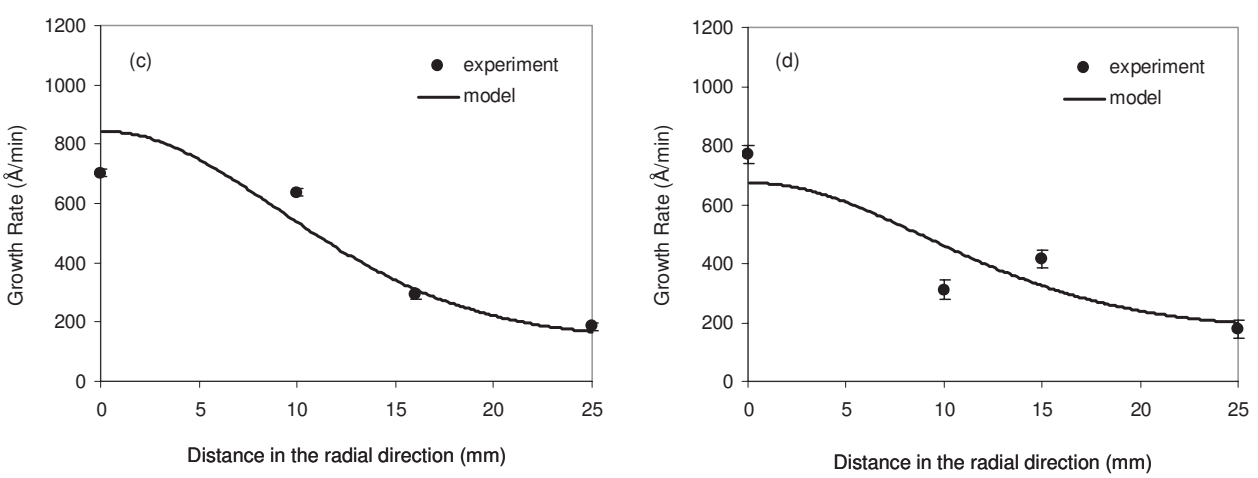
measurements vs model predictions, for the case without the perforated plate, case II.

become higher at the center of the substrate while they decrease in the radial direction. This change in the growth-rate radial profile was observed for the temperature range investigated $\left(220-260^{\circ} \mathrm{C}\right)$ and is also confirmed by the model. To identify the origin of this change in the radial profile of the growth rate, the distribution of the DMEAA over the substrate was further investigated. As expected, the distribution of the DMEAA mass fraction follows a similar trend with that of the growth rate for both cases examined, i.e., with and without the shower plate. The significant increase of the DMEAA mass fraction at the center of the substrate, when the plate is removed from the showerhead system, is due to the dominant convection related to the high velocity of the gas mixture. This is shown in Fig. 7 , which depicts the distribution of the axial component of the velocity along the radial direction of the reactor, with and without the

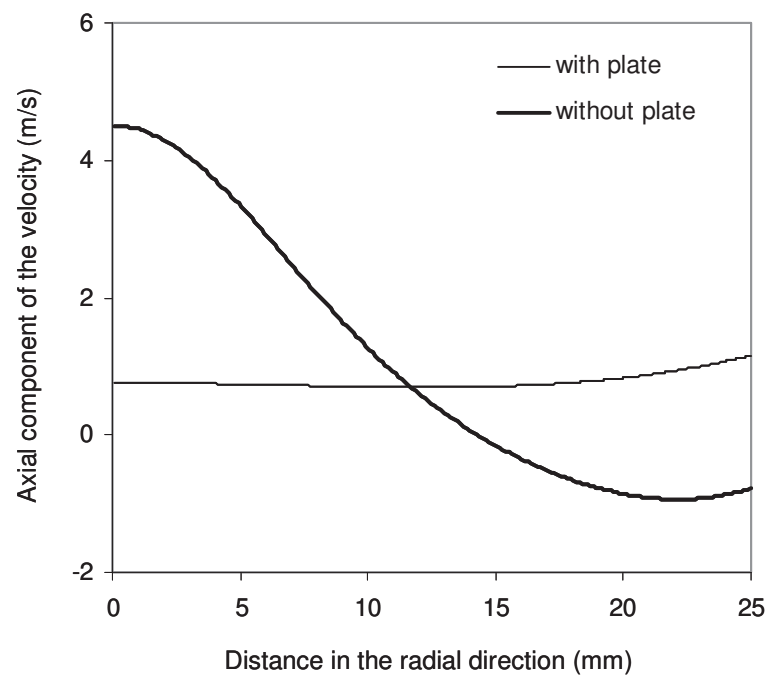

Figure 7. Axial component of the velocity along the radial direction of the reactor, at $5 \mathrm{~mm}$ distance above the substrate. $\mathrm{T}_{\mathrm{s}}=220^{\circ} \mathrm{C}$ and $\mathrm{D}_{\mathrm{p}-\mathrm{s}}$ $=15 \mathrm{~mm}$. plate. The negative values of the axial velocity around $15 \mathrm{~mm}$ indicate the presence of a large recirculation zone that extends outside the showerhead system when the plate is removed, as shown in Fig. 8. The origin of this relatively large zone may be attributed to the local pressure drop due to the velocity increase and the change of the flow direction at the showerhead.

The relative effect of gas-phase and surface reaction in the temperature range of $160-260^{\circ} \mathrm{C}$ can be deduced from the DMEAA consumption, presented in Fig. 9. Note that the points represent the model predictions at the experimental operating conditions tabulated in Table I. The straight lines are linear trend lines of the discrete points. The primary (left) axis is used for the consumption of DMEAA through the gas-phase reaction, while the secondary (right) axis is used for the surface reaction. As expected, the consumption of DMEAA in the gas-phase increases with temperature. Specifically, the DMEAA degradation is almost $82.5 \%$ at $160^{\circ} \mathrm{C}$, while it exceeds the value of $97.5 \%$ at $260^{\circ} \mathrm{C}$ when the shower plate is used. When the perforated plate is removed from the showerhead system, the DMEAA degradation follows a similar trend but the correspond-

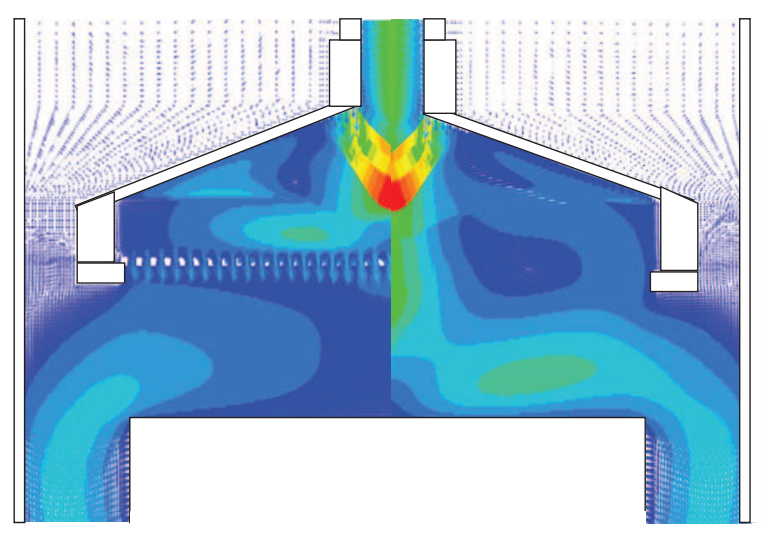

Figure 8. (Color online) Velocity vectors in the MOCVD reactor at $T_{s}$ $=220^{\circ} \mathrm{C}$ with (left) and without (right) the perforated shower plate. 


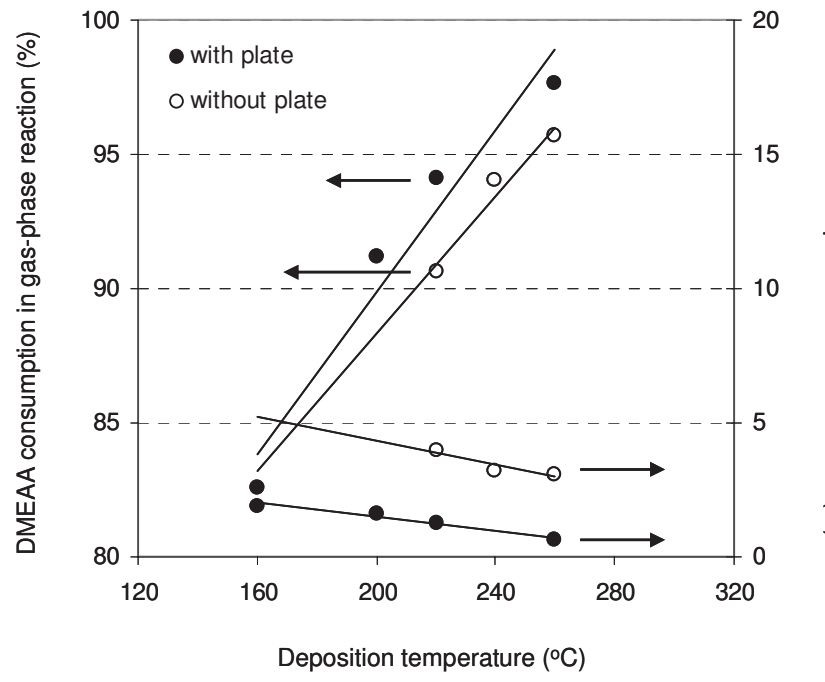

Figure 9. DMEAA consumption (\%) in the gas-phase and in the surface reaction. The straight lines are linear trend lines of the discrete points.

ing values are smaller. For example, at $220^{\circ} \mathrm{C}$ the DMEAA consumption is almost $90.6 \%$ (without plate) to be compared with $94.1 \%$ (with plate). The enhancement of the gas-phase consumption of DMEAA, when the perforated plate is used, may be attributed to the trapping of the gas mixture components inside the large recirculation zone created in the showerhead system. These large percentages of DMEAA degradation in the gas phase are responsible for the decrease of DMEAA consumption through the surface reaction when temperature increases and subsequently for the decrease of the growth rate above $160^{\circ} \mathrm{C}$. Note that the conversion of DMEAA into $\mathrm{Al}$ remains lower than $5 \%$ even for the lower temperature investigated (i.e., $160^{\circ} \mathrm{C}$ ). The slight increase of the surface-reaction yield with increasing $T_{s}$ is attributed to the corresponding decrease of gas-phase degradation of DMEAA.

In the following, the improved reactive transport model is used for a systematic parametric analysis of the MOCVD reactor for $\mathrm{Al}$ growth. All simulations were performed by first selecting a set of reference conditions and then by varying the value of each one of the operating parameters. The reference conditions selected in the present study correspond to the experimental sample exp3 (see Table I). The predictions of the model along with the experimental measurements at reference conditions are shown in Fig. 5c.

Effect of substrate temperature.- Parameter continuation on $\mathrm{T}_{\mathrm{s}}$ was performed and growth rate profiles were calculated for values of temperature from 160 to $300^{\circ} \mathrm{C}$ in steps of $20^{\circ} \mathrm{C}$. Note that the relative growth rate is equal to unity at reference conditions $\left(\mathrm{T}_{\mathrm{s}}\right.$ $=220^{\circ} \mathrm{C}$ ) and that growth rate variation was defined through Eq. 7 . The growth rate is equal to $227.2 \AA / \mathrm{min}$ at reference conditions. The results in Fig. 10a indicate that any increase of the substrate temperature causes a decrease of the growth rate while its variation increases significantly. The decrease of the growth rate is more rapid above $220^{\circ} \mathrm{C}$, a consequence of the significant DMEEA degradation in the gas phase. The increased variation of the growth rate with temperature is also shown in Fig. 10b, where the normalized growth rate profiles at different values of temperature are compared. It can be seen from Fig. 10b that the growth rate variation is greater at a distance of about $16 \mathrm{~mm}$ from the center of the substrate and at the edge of the substrate, i.e., at $25 \mathrm{~mm}$. Moreover, there seems to be a particular distance (around $22.5 \mathrm{~mm}$ ) where the variation of the growth rate starts increasing in the opposite direction.

It appears that any temperature below the reference value performs much better, as accompanied by a greater growth rate with an improved spatial uniformity. However, recall that the experimental growth rate at $160^{\circ} \mathrm{C}$ is lower compared to $220^{\circ} \mathrm{C}$ due to the increased incubation time, as discussed previously. Therefore, a value in the range $200-220^{\circ} \mathrm{C}$ could be considered as an optimal value of substrate temperature.

Effect of reactor pressure.- Parameter continuation on $\mathrm{P}$ was performed and growth rate profiles were calculated for values of pressure in the range of 5-30 Torr, by steps of 5 Torr. The reference value of reactor pressure is 10 Torr. As shown in Fig. 11a, the increase of pressure above the reference value causes a decrease of the growth rate, which approximates the value of $1.6 \AA / \mathrm{min}$ at 30 Torr. On the other hand, note the significant increase of the growth rate by a factor of 7 when pressure is decreased to the lowest value of 5 Torr. Growth rate uniformity is improved at the lower pressure investigated, as also depicted in Fig. 11b. The intersection point of the curves is almost $1 \mathrm{~mm}$ away from the edge of the substrate. It is concluded that any value of the operating pressure lower than the reference one is expected to improve the properties of the $\mathrm{Al}$ films.

Effect of dilution gas flow rate.- Parameter continuation on $\mathrm{F}_{\mathrm{d}}$ was performed and growth rate profiles are calculated for values of flow rate from 105 to $505 \mathrm{sccm}$ in steps of $100 \mathrm{sccm}$. As shown in Fig. 12a, the reference value of $F_{d}$ is $305 \mathrm{sccm}$. The results show that any increase of the flow rate of dilution nitrogen causes an increase of the growth rate. It appears that the dominant convection related to higher flow rates, and thus higher velocities, yields higher DMEAA concentrations and therefore higher growth rates. This trend in the growth rate is followed by a decrease of growth rate variation, as depicted in Fig. 12b. The increased values of the growth rate, mainly in the center of the substrate, are responsible for the improvement of the growth rate uniformity at the higher values of the flow rate.

\section{Conclusions}

This paper presents an improved computational fluid dynamics model that enables the elucidation of the reaction and transport interplay in the growth process of Al films from DMEAA. The reactive transport model was successfully constructed under the framework of PHOENICS CFD software to simultaneously solve the conservation equations of mass, momentum, and energy under steady-state conditions. A simplified model previously developed to describe the Al-MOCVD under low-pressure conditions was used as
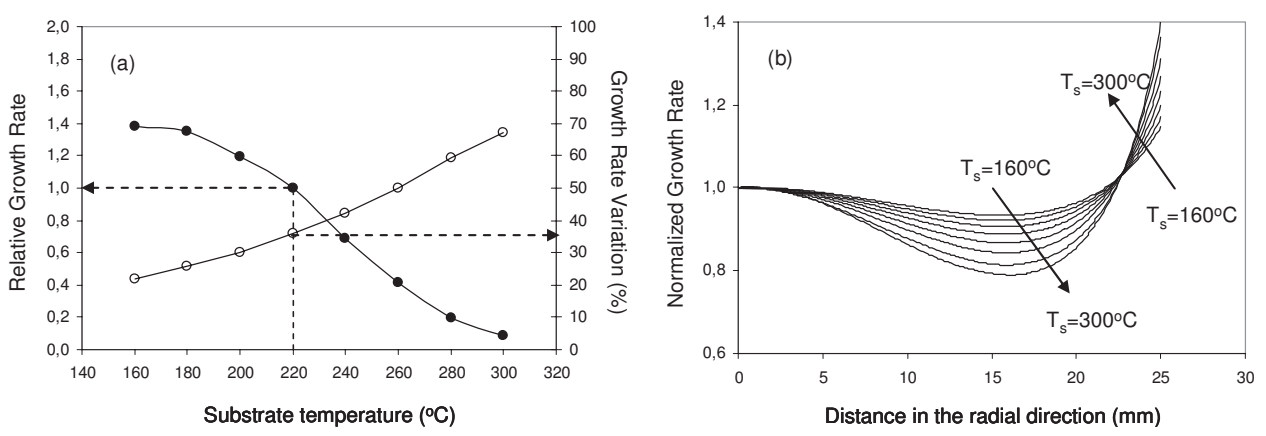

Figure 10. (a) Relative growth rate and growth rate variation as a function of substrate temperature. (b) Normalized growth rate profile at different values of substrate temperature, $\mathrm{T}_{\mathrm{s}}$ (in steps of $20^{\circ} \mathrm{C}$ ). 

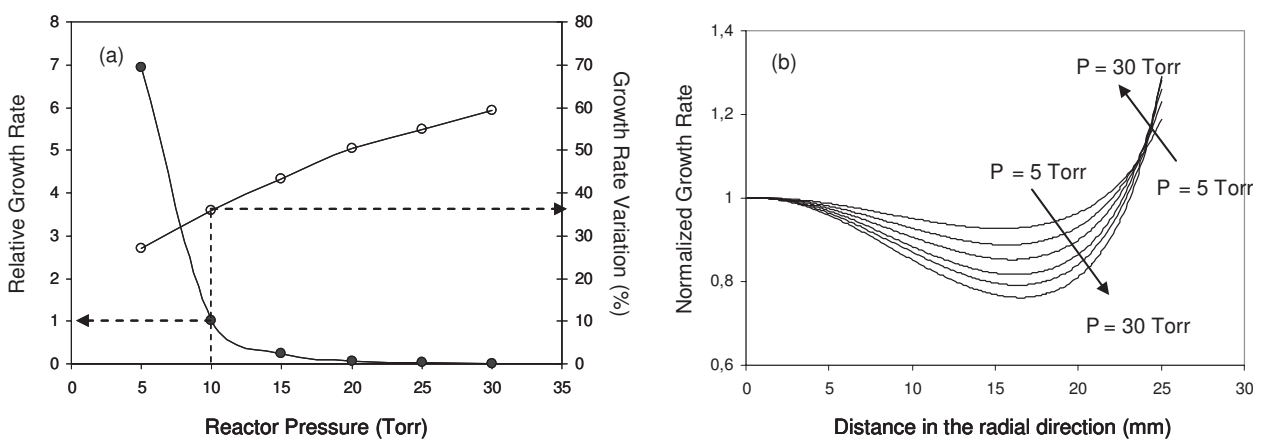

Figure 11. (a) Relative growth rate and growth rate variation as a function of reactor pressure. (b) Normalized growth rate profile at different values of reactor pressure, $\mathrm{P}$ (in steps of 5 Torr).
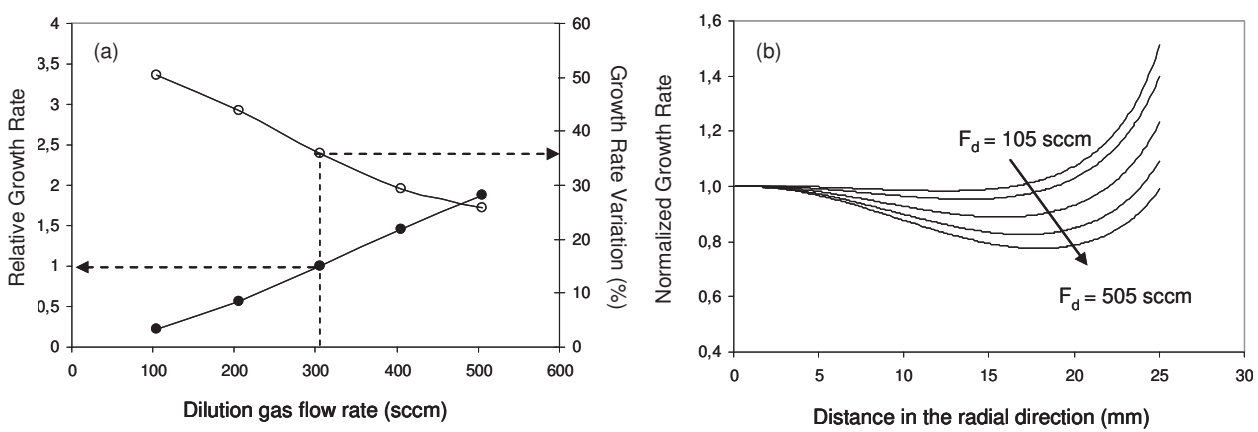

Figure 12. (a) Relative growth rate and growth rate variation as a function of dilution gas flow rate. (b) Normalized growth rate profile at different values of dilution gas flow rate, $F_{d}$ (in steps of $100 \mathrm{sccm})$.

a reference model to establish the improvement of the present model. Two important refinements were found to improve the model predictions, namely the detailed description of the perforated shower plate, which influences the spatial distribution of the growth rate over the substrate, and the addition of the gas-phase reaction, which is responsible for the decrease of the growth rate at higher values of temperature.

The improved model was validated against experimental measurements that demonstrate the influence of the growth temperature, of the distance between the showerhead system and the heated substrate, and of the use of the perforated plate in the gas delivery system. The good agreement between model predictions and experimental data fully supports the gas and surface chemistry reported in the literature. Moreover, simulation results revealed the important effect of the gas-phase degradation of DMEAA in comparison to the limited contribution of the surface reaction to the film growth on the heated substrate.

Based on the improved model, simulation results indicated that the growth rate and its spatial variation strongly depend on the growth temperature, on the reactor pressure, and on the inlet flow rate of the dilution gas. It is concluded that the improved reactive transport model can be used as a tool to guide future experimental work toward optimal parameter values for desired growth rates and growth shapes of Al-based complex metallic alloys.

\section{Acknowledgments}

This work was supported by the General Secretariat for Research and Technology of Greece and by the French Ministry of Foreign Affairs through the Programme for "Greece-France cooperation in Research and Technology" (contract 15207XG, 2006-08). The support of the Agence Nationale de la Recherche in France, through contract NT05-3 41834, and of the European Commission through the network of excellence NMP3-CT-2005-500140 is also acknowledged.

Centre Interuniversitaire de Recherche et d'Ingénierie des Matériaux assisted in meeting the publication costs of this article.

\section{List of Symbols}

A pre-exponential factor of reaction rate

gravity acceleration, $\mathrm{m} \mathrm{s}^{-2}$

component of the velocity vector, $\mathrm{m} \mathrm{s}^{-1}$

u velocity vector, $\mathrm{m} \mathrm{s}^{-1}$

$c_{p}$ specific heat, $\mathrm{J} \mathrm{kg}^{-1} \mathrm{~K}^{-1}$

$\mathrm{d}$ diameter of the holes of the shower plate

D binary diffusion coefficient, $\mathrm{m}^{2} \mathrm{~s}^{-1}$

$\mathrm{D}^{\mathrm{T}}$ thermal diffusion coefficient, $\mathrm{kg} \mathrm{m}^{-1} \mathrm{~s}^{-1}$

$D^{\text {eff }}$ effective diffusion coefficient, $\mathrm{m}^{2} \mathrm{~s}^{-1}$

$\mathrm{D}_{\mathrm{p}-\mathrm{s}}$ distance between the shower plate and the substrate, $\mathrm{mm}$

exp experimental sample

E activation energy, $\mathrm{kcal} \mathrm{mol}^{-1}$

$F_{d}$ flow rate of dilution gas, sccm

$\mathrm{H}$ enthalpy of formation, $\mathrm{J} \mathrm{mol}^{-1}$

I unity tensor

j diffusive mass flux, $\mathrm{kg} \mathrm{m}^{-2} \mathrm{~s}^{-1}$

$\mathrm{k}$ kinetic rate

1 with respect to experimental sample

$\mathrm{L}$ thickness of the shower plate

$\mathrm{M}$ gas mixture molecular weight, $\mathrm{kg} \mathrm{mol}^{-1}$

$\mathrm{M}_{\mathrm{s}}$ molecular weight of deposited (solid) material, $\mathrm{kg} \mathrm{mol}^{-1}$

$\mathrm{N}$ number of gas species

$\mathrm{P}$ pressure, $\mathrm{Pa}$

$\mathrm{R}$ gas constant, $8.34132 \mathrm{~J} \mathrm{~mol}^{-1} \mathrm{~K}^{-1}$

$R_{d}$ deposition rate, mol m $\mathrm{m}^{-2} \mathrm{~s}^{-1}$

$\mathrm{R}^{\mathrm{D}}$ maximum diffusive mass flux at the surface, $\mathrm{kg} \mathrm{m}^{-2} \mathrm{~s}^{-1}$

$\mathrm{R}^{\mathrm{g}}$ gas phase reaction rate, $\mathrm{mol} \mathrm{m}^{-3} \mathrm{~s}$

$\mathrm{R}^{\mathrm{s}} \quad$ surface reaction rate, $\mathrm{mol} \mathrm{m} \mathrm{m}^{-2} \mathrm{~s}$

$\mathrm{S}$ generalized source term, various

$S^{0}$ constant part of the generalized source term, various

$S^{\prime} \quad$ linear part of generalized source term, various

$\mathrm{T}$ temperature, $\mathrm{K}$

$t_{d}$ duration of experiment, min

Greek

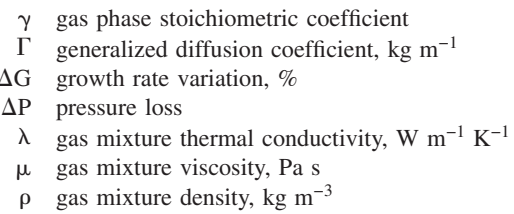


$\rho_{\mathrm{s}}$ density of deposited (solid) material, $\mathrm{kg} \mathrm{m}^{-3}$

$\sigma$ surface stoichiometric coefficient

$\phi$ generalized variable $\phi$, various

$\omega$ gas species mass fraction

Subscripts

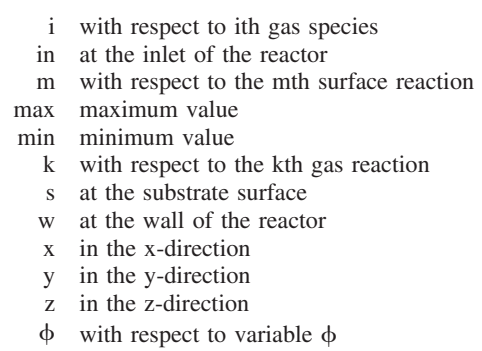

Superscripts

$$
\begin{aligned}
& \mathrm{C} \text { due to concentration gradient } \\
& \mathrm{T} \text { due to temperature gradients }
\end{aligned}
$$

\section{References}

1. J.-M. Dubois, Useful Quasicrystals, World Scientific, Singapore (2005).

2. E. Huttunen-Saarivitra, J. Alloys Compd., 363, 150 (2004).

3. D. I. Fotiadis, S. Kieda, and K. F. Jensen, J. Cryst. Growth, 102, 441 (1990).

4. M. L. Hitchman and K. F. Jensen, Chemical Vapor Deposition: Principles and Applications, Academic, London (1993).

5. C. R. Kleijn, Thin Solid Films, 365, 294 (2000).

6. S. Mazumder and S. A. Lowry, J. Cryst. Growth, 224, 165 (2001).

7. C. E. C. Dam, A. P. Crzegorczyk, P. R. Hageman, R. Dorsman, C. R. Kleijn, and P. K. Larsen, J. Cryst. Growth, 271, 192 (2004).

8. T. C. Xenidou, A. G. Boudouvis, D. M. Tsamakis, and N. C. Markatos, J. Electrochem. Soc., 151, C757 (2004).

9. L. Kadinski, V. Merai, A. Palekh, H. Ramer, E. A. Armour, R. Stall, A. Gurary, A. Galyukov, and Y. Marakov, J. Cryst. Growth, 261, 175 (2004).

10. T. C. Xenidou, A. G. Boudouvis, N. C. Markatos, D. Samélor, F. Senocq, N. PrudHomme, and C. Vahlas, Surf. Coat. Technol., 201, 8868 (2007).

11. M. G. Simmonds, W. L. Gladfelter, R. Nagaraja, W. W. Szymanski, K.-H. Ahn, and P. H. McMurry, J. Vac. Sci. Technol. A, 9, 2782 (1991).

12. J. Han, K. F. Jensen, Y. Senzaki, and W. L. Gladfelter, Appl. Phys. Lett., 64, 425 (1994).

13. X. Li, B.-Y. Kim, and S.-W. Rhee, Appl. Phys. Lett., 67, 3426 (1995).

14. B.-Y. Kim, X. Li, and S.-W. Rhee, Appl. Phys. Lett., 68, 3567 (1996).

15. J.-H. Yun and S.-W. Rhee, J. Mater. Sci.: Mater. Electron., 9, 1 (1998).

16. J.-H. Yun, M.-Y. Park, and S.-W. Rhee, J. Vac. Sci. Technol. A, 16, 419 (1998).

17. J.-H. Yun, B.-Y. Kim, and S.-W. Rhee, Thin Solid Films, 312, 259 (1998).

18. T. W. Jang, W. Moon, J. T. Baek, and B. T. Ahn, Thin Solid Films, 333, 137
(1998).

19. Y. Neo, M. Miwano, H. Mimura, and K. Yokko, Appl. Surf. Sci., 142, 443 (1999).

20. M. Delmas, D. Poquillon, Y. Kihn, and C. Vahlas, Surf. Coat. Technol., 200, 1413 (2005)

21. M. Delmas and C. Vahlas, J. Electrochem. Soc., 154, D538 (2007).

22. CHAM Ltd., PHOENICS software, London (2008).

23. N. C. Markatos, Rev. Inst. Fr. Pet., 48, 631 (1993).

24. T. Nakajima, M. Nakatomi, and K. Yamashita, Mol. Phys., 101, 267 (2003).

25. H. Matsuhashi, C.-H. Lee, T. Nishimura, K. Masu, and K. Tsubouchi, Mater. Sci. Semicond. Process., 2, 303 (1999).

26. J. W. Turley and H. W. Rinn, Inorg. Chem., 8, 18 (1969).

27. G. Wahl, Thin Solid Films, 40, 13 (1977).

28. K. F. Jensen and D. B. Graves, J. Electrochem. Soc., 130, 1950 (1983).

29. M. E. Coltrin, R. J. Kee, and J. Miller, J. Electrochem. Soc., 131, 425 (1984).

30. G. Evans and R. Greif, J. Heat Transfer, 109, 928 (1987).

31. H. K. Moffat and K. F. Jensen, J. Electrochem. Soc., 135, 459 (1988).

32. C. R. Kleijn and C. J. Hoogendoorn, Chem. Eng. Sci., 46, 321 (1991).

33. H. Habuka, T. Nagoya, M. Katyama, M. Shimada, and K. Okuyama, J. Electrochem. Soc., 142, 4272 (1995)

34. M. E. Coltrin, R. J. Kee, and G. H. Evans, J. Electrochem. Soc., 136, 819 (1989).

35. M. D. Allendorf and R. J. Kee, J. Electrochem. Soc., 138, 841 (1991).

36. R. Arora and R. Pollard, J. Electrochem. Soc., 138, 1523 (1991).

37. I. Lengyel and K. F. Jensen, Thin Solid Films, 365, 231 (2000).

38. K. J. Kuijlaars, C. R. Kleijn, and H. E. A. van den Akker, Solid-State Electron., 42, A43 (1998).

39. S. Kommu, G. M. Wilson, and B. Khomami, J. Electrochem. Soc., 147, 1538 (2000).

40. M. Grujicic, G. Cao, and B. Gersten, Appl. Surf. Sci., 199, 90 (2002).

41. W. T. Cheng, H. C. Li, and C. N. Huang, Chem. Eng. J., 137, 603 (2008).

42. R. P. Parikh and R. A. Adomaitis, J. Cryst. Growth, 286, 259 (2006)

43. T. C. Xenidou, N. Prud'homme, L. Aloui, C. Vahlas, N. C. Markatos, and A. G. Boudouvis, ECS Trans., 25(8), 1053 (2009).

44. C. R. Kleijn, in Computational Modeling in Semiconductor Processing, M. Meyyappan, Editor, p. 97, Artech House, Boston, MA (1995).

45. O. Hirschfelder, C. F. Curtiss, and R. B. Bird, Molecular Theory of Gases and Liquids, John Wiley \& Sons, New York (1967).

46. T. C. Xenidou, M. K. Koukou, A. G. Boudouvis, and N. C. Markatos, J. Phys. IV, 11, Pr3183 (2001)

47. W.-S. Choi, J.-M. Ahn, J.-H. Bae, S.-K. Suh, J.-H. Yun, and S.-W. Rhee, in Thirteenth International Conference on Chemical Vapor Deposition (CVD XIII), T. M. Besmann, McD. Robinson, R. K. Ulrich, M. D. Allendorf, M. L. Hitchman, and H. Komiyama, Editors, PV 96-5, p. 131, The Electrochemical Society Proceedings Series, Pennington, NJ (1996).

48. J. I. Ulacia, S. Howell, H. Korner, and Ch. Werner, Appl. Surf. Sci., 38, 370 (1989).

49. C. R. Kleijn, C. J. Hoongendoorn, A. Hasper, J. Holleman, and J. Middelhoek, J. Electrochem. Soc., 138, 509 (1991).

50. S. V. Patankar, Numerical Heat Transfer and Fluid Flow, Taylor \& Francis, London (1980).

51. F. M. White, Viscous Fluid Flow, McGraw-Hill, New York (1984), 